\title{
Dermatopatía de origen Hepatobiliar. Un enfoque integral desde la medicina Biorreguladora de sistemas. Reporte de Caso
}

\author{
Stephany Velasquez ${ }^{1}$ \\ Corresponding Author: Stephany Velasquez, 03stephy@gmail.com \\ ${ }^{1}$ 03stephy@gmail.com
}

\begin{abstract}
La dermatopatía de origen hepatobiliar es una alteración sistémica que poco se ha descrito en caninos, pero está bien documentado en humanos, cursa con manifestaciones cutáneas importantes que pueden ser muy variadas, pero su reconocimiento temprano puede ser útil para identificar hepatopatías. Los cambios cutáneos pueden ser la primera pista de que un paciente tiene enfermedad hepática. El presente reporte, describe el abordaje integrativo de un canino macho de raza Pastor Alemán de 4 años de edad con lesiones dermatológicas asociadas a alteraciones hepatobiliares tratado con medicina biorreguladora a través de redes. Las lesiones presentadas eran costrosas, areatas, eritematosas en zona dorsal toraco-lumbar, costal y miembros posteriores. Había prurito, descamación generalizada, hipotricosis y alopecia multifocal. El diagnostico se basó en la presentación clínica, análisis de sangre completos, examen ultrasonográfico y exámenes dermatológicos. Los principales diagnósticos incluían; Dermatopatía de origen hepatobiliar, enfermedad hepatobiliar crónica, colelitiasis, enfermedad renal crónica y hemoparásitos. Se realizó bajo los principios de la medicina homotoxicologica; detoxificación básica, inmunomodulación y soporte al órgano, logrando una resolución completa del paciente con resultados de laboratorio dentro de parámetros normales y sin reincidencia de los síntomas. Reconocer los diversos signos cutáneos es fundamental para diagnosticar a tiempo las enfermedades del hígado. Hacer un buen manejo integral y profundizar más allá del sistema que manifiesta los síntomas, permitirá tener resultados mas satisfactorios y la posibilidad de solucionarlos desde sus diferentes sistemas asociado a redes.
\end{abstract}

Keywords: Dermatitis, skin diseases, Medicina Alternativa, Hígado, Medicina Biorreguladora, Hepatopatía, Reporte de caso

\section{Introduction}

Las dermatopatías se convierten en un desafío en la medicina veterinaria, dado que las lesiones se pueden manifestar como la expresión de alteraciones sistémicas imperceptibles a simple vista. La mayoría de las afecciones involucran factores nutricionales, metabólicos. hepáticos e inmunológicos que desintegran la estabilidad del tegumento y su correcta homeodinamia (FOGEL Y MANZUC, 2009). Las hepatopatías se asocian a diversos signos cutáneos, aunque ninguno de ellos es específico. Los cambios cutáneos observados pueden deberse a alteraciones primarias del hígado y a una gran variedad de trastornos que cursan con cambios en muchos órganos, incluidos el hígado y la piel. (SAENZ, 2011). La dermatopatía de origen hepatobiliar es una alteración sistémica que poco se ha descrito en caninos, pero está bien documentada en humanos, cursa con manifestaciones cutáneas importantes que pueden ser muy variadas, pero su reconocimiento temprano puede ser útil para identificar hepatopatías. (RAHZIN Y COL, 2019), (DOGRA Y COL, 2011). En la mayoría de los casos tienen una evolución crónica y progresiva, pero es en la piel donde pueden aparecer signos de 
enfermedades internas y cerca del 15 al 20\% de los pacientes humanos con enfermedades hepáticas crónicas aparecen con lesiones dermatológicas como manifestaciones extrahepáticas. (ESPINOZA Y COL 2012). En caninos no se encuentran tantos reportes sobre esta asociación, pero es importante tenerla en cuenta para identificar a través de la piel alteraciones hepáticas que estén en curso.

En humanos tanto la enfermedad hepática aguda como la crónica pueden manifestarse en la piel. La enfermedad hepática crónica de cualquier origen puede causar hallazgos cutáneos, uno de ellos es el prurito que es la manifestación mas común. Pero también se incluyen, ictericia, xantomas, eritema palmar, caída del cabello y cambios en las uñas. (PATEL Y COL, 2020), (MELA Y COL, 2003), (KOULAOUZIDIS Y COL, 2007). Así mismo, los perros y gatos con enfermedad hepática pueden presentar signos inespecíficos como, anorexia, letargo, vómitos o ictericia. La causa de la hepatitis crónica en perros generalmente es desconocida, y el tratamiento se centra en intentar retrasar la progresión de la enfermedad y tratar los signos clínicos (NELSON Y COUTO, 2020).

Otros hallazgos que asocian trastornos dermatológicos como placas costrosas, eritematosas, ulceraciones y alopecia están en el síndrome Hepatocutaneo (DRAGONETTI, 2006). El síndrome Hepatocutaneo es una afección de la piel en asociación con ciertas enfermedades hepáticas que generalmente tiene un mal pronóstico. La fisiopatología y las causas subyacentes en los perros siguen sin estar claras, y es probable que sea multifactorial. La patogenia subyacente en la piel parece ser causada por concentraciones de aminoácidos circulantes anormalmente bajas y, por lo tanto, desnutrición de la piel. Esto genera degeneración de los queratinocitos, edema y tumefacción de estas células como del conjunto de la epidermis (SALAS Y GRANDEZ, 2013). El pronóstico es muy malo a menos que se pueda identificar y tratar la causa subyacente. El tratamiento se basa en suplementación de aminoácidos, proteínas, terapia sintomática, protectores hepáticos, antioxidantes, antibioterapia y corticoterapia que mejoran, pero no curan definitivamente ya que, con el tiempo, vuelven a empeorar (NELSON Y COUTO, 2020), (SALAS Y GRANDEZ, 2013). Un artículo donde describen el caso de un conejo con dermatitis exfoliativa asociada a un transtorno hepático inflamatorio crónico, muestra que el mecanismo por el que las lesiones cutáneas se producen parece relacionado con una respuesta inmunomediada producida por linfocitos $\mathrm{T}$ originados en los órganos internos involucrados que atacan a la epidermis y dermis. Pero también puede estar relacionado con una hepatitis de origen no inmunomediado, por lo que diferentes patologías hepáticas pueden dar lugar a esa enfermedad (ISASI Y COL, 2012). En el presente artículo se describe un caso clínico de dermatopatía asociada a un transtorno hepatobiliar tratado con medicina biorreguladora de sistemas y su enfoque de medicina en redes.

\section{Timeline}

\footnotetext{
2019-08-28 — El paciente inicia historial clínico en otro centro veterinario donde diagnostican Gastroenteritis parasitaria e identifican quistes prostáticos y sedimento a nivel de vejiga.

2019-08-30 - Se realiza castración y se inicia tratamiento con dipropionato de imidocarb por sospecha de hemoparásitos. El tratamiento en casa se realiza con prednisolona a 1.6 $\mathrm{mg} / \mathrm{kg}$ con dosis decreciente, doxiciclina a $5 \mathrm{mg} / \mathrm{kg}$ y Rinom- V granulado.
} 


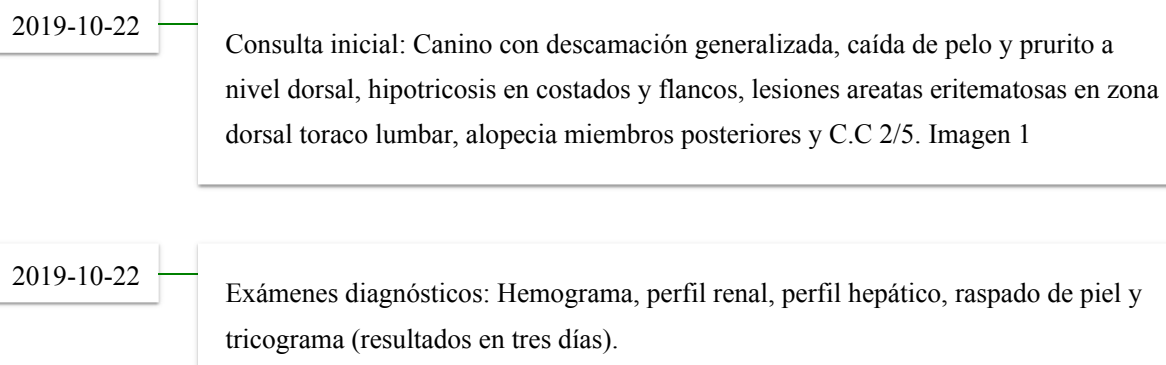
nivel dorsal, hipotricosis en costados y flancos, lesiones areatas eritematosas en zona dorsal toraco lumbar, alopecia miembros posteriores y C.C $2 / 5$. Imagen 1

Tratamiento inicial: Baños medicados con shampoo de clorhexidina $2 \%$ y miconazol $2 \%$, loción dermatológica a base de clotrimazol, dexametasona y neomicina, y un suplemento multivitaminco con omegas 3,6 y 9 .

Resultados de laboratorio: Leucositosis Leve, Bilirrubinemia, aumento de ácidos biliares grave, azotemia por incremento de creatinina sérica, BUN y urea de forma leve, aumento leve de fosfatasa alcalina y leve hipoglicemia. Imagen 2

Diagnósticos diferenciales: Dermatopatia de origen Hepatobiliar, Ehrlichiosis canina, Colelitiasis, Enfermedad renal crónica. Se inicia tratamiento con Ursacol $15 \mathrm{mg} / \mathrm{kg}$ cada 24 horas por 20 días y Nutrición con dieta renal.

Continúan lesiones dermatológicas, ya no hay prurito pero aumenta en exceso la caída de pelo generalizada evidenciando más zonas alopécicas. Se suspende loción dermatológica y Se inicia tratamiento biorregulador. Imagen 3

Exámenes de control y Ecografia. Imagen 4. Se evidencian 2 Cistolitos en vesicula biliar y quistes renales. Se inicia medicación con Chelidonium Homaccord NT Gotas, 10 gotas via oral SID por 20 días. Se suspende Ursacol por falta de efectividad.

2019-11-21 - Resultados de laboratorio: Todos los parámetros dentro de los rangos normales. Imagen 5 .

Condición corporal 3.5/5, no presenta lesiones eritematosas, cesa caída de pelo. Resolución completa de lesiones dermatológicas. Se realiza control ecográfico, disminuye tamaño cistolito. No se evidencian los quistes renales. Imagen 6,7 y 8

2021-12-04 Luego de 2 años que se hizo tratamiento biorregulador el paciente sigue estable y gozando de buena salud

\section{$\underline{\text { Narrative }}$}


Paciente canino, macho, Pastor Alemán de 4 años de edad, que llega a consulta por descamación generalizada, prurito, eritema focalizado, hipotricosis. alopecia multifocal y lesiones areatas eritematosas en zona dorsal toraco-lumbar, costal y miembros posteriores. El paciente es procedente de una ciudad de clima cálido (Yopal, Casanare) con historial de hospitalización por gastroenteritis parasitaria y orquiectomía por quistes prostáticos, presenta antecedentes en exámenes de laboratorio de leucocitosis marcada y creatinina de $2 \mathrm{mg} / \mathrm{dL}$ con un aparente desarrollo de enfermedad renal. Historial de tratamiento con Doxiciclina $5 \mathrm{mg} / \mathrm{kg}$ y prednisolona $1.6 \mathrm{mg} / \mathrm{kg}$ durante 28 días, por una posible Ehrlichiosis sin exámenes diagnósticos confirmativos. Después de múltiples exámenes complementarios se establece como diagnósticos diferenciales Dermatopatia de origen hepatobiliar; Enfermedad Renal Crónica; Colelitiasis y Ehrlichiosis. Con pronostico reservado. Generalmente las enfermedades hepáticas con manifestaciones cutáneas como el síndrome hepato cutáneo tienen muy mal pronostico, porque se desconoce la causa subyacente y el tratamiento esta encaminado a mejorar la calidad de vida e incrementar la supervivencia del paciente.

\section{Diagnostics}

\begin{tabular}{|c|c|c|c|}
\hline DATE & TYPE & VALUE & UNIT \\
\hline $2019-10-22$ & Weight & 28 & $\mathrm{~kg}$ \\
\hline 2019-10-24 & Bile acids, total & 47 & $\mu \mathrm{mol} / \mathrm{L}$ \\
\hline $2019-10-25$ & Bilirubin, conjugated (direct) & 0.5 & $\mathrm{mg} / \mathrm{dL}$ \\
\hline $2019-10-25$ & RBC (total red blood cells) & 8.05 & $\mathrm{M} / \mathrm{mm}^{\wedge} 3$ \\
\hline $2019-10-25$ & Glucose & 54.03 & $\mathrm{mg} / \mathrm{dL}$ \\
\hline $2019-10-25$ & WBC (total white blood cells) & 18.5 & thousand cells/cubic mm \\
\hline $2019-10-25$ & BUN (blood urea nitrogen) & 36.68 & $\mathrm{mg} / \mathrm{dL}$ \\
\hline $2019-10-25$ & Hct (hematocrit) & 54.6 & $\%$ \\
\hline $2019-10-25$ & Bilirubin, total & 1.1 & $\mathrm{mg} / \mathrm{dL}$ \\
\hline $2019-10-25$ & Creatinine & 1.83 & $\mathrm{mg} / \mathrm{dL}$ \\
\hline $2019-10-25$ & Basophils & 370 & $\mathrm{IU} / \mathrm{L}$ \\
\hline 2019-11-20 & Bilirubin, conjugated (direct) & 0.37 & $\mathrm{mg} / \mathrm{dL}$ \\
\hline 2019-11-20 & Bilirubin, total & 0.48 & $\mathrm{mg} / \mathrm{dL}$ \\
\hline
\end{tabular}




$\begin{array}{llll}2019-11-20 & \text { WBC (total white blood cells) } & 15.2 & \text { thousand cells/cubic mm } \\ 2019-11-20 & \text { Creatinine } & 1.28 & \mathrm{mg} / \mathrm{dL} \\ 2019-11-20 & \text { Hct (hematocrit) } & 47.3 & \% \\ 2019-11-21 & \text { Bile acids, total } & 18 & \mu \mathrm{mol} / \mathrm{L} \\ & & & \\ 2019-12-04 & \text { Weight } & 35 & \mathrm{~kg}\end{array}$

\section{Perspective}

El propietario del paciente habia buscado diferentes opciones terapéuticas, para una resolución de las diversas patologías que estaba mostrando el paciente a lo largo de su vida, sin resultados positivos. En la medicina biorreguladora encontró un manejo integral y resultados favorables, sin importar que inicialmente el motivo de consulta era por alteraciones dermatológicas, al realizar una consulta desde el concepto de medicina biorreguladora se identificaron múltiples alteraciones sistémicas que favorecía las alteraciones del tegumento. Al realizar un tratamiento global enfocado al restablecimiento del equilibrio de la interacción y función de los órganos y sistemas involucrados, identificamos una mejoría y resolución del paciente, siendo una oportunidad para la medicina biorreguladora de afrontar a pacientes de este tipo con terapias mas integrales, demostrando una vez mas la efectividad de los medicamentos biorreguladores manejándolos a diferentes niveles y_grupos de regulación.

\section{Discussion}

En la práctica diaria de la clínica de pequeños animales, los pacientes dermatológicos representan uno de los principales motivos de consulta al Veterinario (CARLOTTI, 2004). Estos pacientes dermatológicos se convierten en un desafío, dado que las lesiones muchas veces se manifiestan como reflejo de problemas sistémicos imperceptibles a simple vista. La mayoría de las afecciones involucran factores nutricionales, metabólicos, hepáticos e inmunológicos que desintegran la estabilidad del tegumento y su correcta homeostasis (FOGEL Y MANZUC, 2009).

Las hepatopatías se asocian a diversos signos cutáneos, aunque ninguno de ellos es específico, los cambios cutáneos observados pueden deberse a alteraciones primarias del hígado y a una gran variedad de trastornos que cursan con cambios en muchos órganos, incluidos el hígado y la piel.

(SAENZ, 2011). En la mayoría de los casos tienen una evolución crónica y progresiva, pero es en la piel donde pueden aparecer signos de enfermedades internas y cerca del 15 al $20 \%$ de los pacientes humanos con enfermedades hepáticas crónicas aparecen con lesiones dermatológicas como manifestaciones extrahepáticas. (ESPINOZA Y COL 2012). En caninos no se encuentran tantos reportes sobre esta asociación, pero es importante tenerla en cuenta para identificar a través de la piel alteraciones hepáticas que estén en curso. En este reporte de caso se observaron diversos hallazgos cutáneos que podían ser causados por enfermedades primarias de la piel como dermatofitosis, foliculitis bacteriana, dermatitis acaricida, pero se descartaron por los resultados de los exámenes de laboratorio. Identificar que esas manifestaciones cutáneas eran el reflejo de problemas hepáticos fue el reto porque en medicina convencional poco se realiza esa asociación hígado-piel. Se espera tener más estudios en caninos que relacionen estas manifestaciones cutáneas con problemas hepáticos como se encuentran bien reportadas en bibliografía humana. 
En literatura de medicina humana reportan que el prurito es el primer síntoma asociado a problemas hepáticos y que la acumulación de sales biliares, ácidos biliares y bilirrubinas han sido considerados los responsables del prurito colestásico (DOGRA, 2011). Esto lo relacionan en que las sales biliares actúan sobre el hepatocito para liberar un factor pruritogénico; las sales biliares hidrófobas se acumulan en hígado debido a la colestasis, alteran la fluidez de membrana, inducen desprendimiento de la membrana plasmática y liberan un pruritógeno que actúa dentro del SNC o periférico para promover la percepción de la picazón (MELA, 2003). En el caso del pastor alemán se evidenció el prurito desde sus inicios hasta la mitad del tratamiento probablemente inducido por la acumulación de ácidos biliares que liberaban el pruritogeno en SNC. Este signo, aunque inespecífico, se debe tener en cuenta para el diagnóstico temprano de enfermedades hepatobiliares en caninos.

Si comparamos, los perros y gatos con enfermedad hepática también pueden presentar signos inespecíficos como, anorexia, letargo, vómitos o ictericia. La causa de la hepatitis crónica en perros generalmente es desconocida, y el tratamiento se centra en intentar retrasar la progresión de la enfermedad y tratar los signos clínicos (NELSON Y COUTO, 2020). Basados en el principio que la piel funciona como una ventana a nuestra salud en general (DOGRA Y COL, 2011). Se comprende que con el enfoque integral de tratamiento con medicina biorreguladora se logró no solo tratar los signos clínicos asociados al hígado y la piel, sino tratar los demás sistemas involucrados que apoyan la biorregulación del organismo como el sistema gastrointestinal y el inmunológico. De la misma forma, el síndrome hepatobiliar y la colelitiasis presentan como signos clínicos anorexia, vomito, diarrea, dolor abdominal e ictericia (RACANCO y col, 2009). Cuando existe obstrucción del sistema biliar extra-hepático en pequeñas especies, la bioquímica sanguínea presenta aumento de la bilirrubina total y conjugada, incremento en las concentraciones de fosfatasa alcalina (FA), de alanin amino transferasa (ALT) y de ácidos biliares. Los resultados observados en los exámenes paraclínicos coinciden con los obtenidos por Rodríguez y col. en el aumento de FA, Ácidos biliares, Bilirrubinas totales- diferenciadas y proteínas plasmáticas que muestran una hepatopatía inducida por la saturación de compuestos tóxicos; estos compuestos probablemente se deben al tratamiento prolongado con corticoides, antibióticos y toxinas presentes anteriormente en el organismo.

En una palabra, la piel moviliza una gran parte de los macronutrientes y micronutrientes aportados por el alimento, un desequilibrio en el aporte de aminoácidos, ácidos grasos, vitaminas u oligoelementos altera las funciones de barrera y de protección inmunitaria (FOSTER Y FOIL, 2012). En el caso clínico presentado se deduce que la alteración en los mecanismos de protección inmunitaria de la piel y el desbalance nutricional con el que venía el paciente, probablemente desencadenó las manifestaciones dermatológicas. Parte de esa protección inmunológica la aportan los órganos linfoides secundarios como el MALT (Tejido linfoide asociado a Mucosas) que ejerce un papel importante en la estabilización de la barrera de protección inmunitaria (LOPEZ y col, 2010). De la misma forma existe una serie de evidencias científicas que respaldan la función inmunológica en la piel, Castrillón comenta que la piel puede considerarse un órgano linfoide de primer nivel y que según unos autores llamaron a este mecanismo, el tejido linfoide asociado a la piel (SALT, por sus siglas en inglés) (CASTRILLON y col, 2008). De aquí radica la importancia de manejar la medicina biorreguladora basada en los 3 pilares de la homotoxicología: 1) la detoxificación básica; que activa las funciones emuntoriales del hígado y del riñón depurando la matriz extracelular para obtener un óptimo medio celular. 2) La inmunomodulación basada en la autorregulación del sistema inmunológico y 3 ) el soporte al órgano que permite recuperar o mantener una función celular normal. Así mismo, el soporte celular es fundamental en todos los casos, en particular para mejorar la oxigenación celular, ésta se lleva a cabo actuando a nivel del ciclo de Krebs y de la cadena respiratoria mitocondrial, respectivamente (ZURITA Y VALLEJO, 2017), (GARZON, 2015). 
Es importante considerar que en medicina biológica la matriz extracelular constituye un elemento esencial en la etiología y tratamiento de las enfermedades debido a su estrecha relación con el aporte e intercambio de nutrientes. Si el organismo presenta una matriz extracelular sana los procesos de interacción y soporte se ejecutan con normalidad (ADELWOHRER, 2004). Por ello es fundamental realizar detoxificación siempre que se quiera iniciar tratamiento biorregulador para generar un ambiente propicio. La terapia biorreguladora en el pastor alemán se inicia con detoxificación básica debido al historial de tratamiento previo con medicina alopática prolongada; en este punto se utilizó Nuxeel Homaccord ad. us. vet., Lymphomyosot N. y Berbeel Homaccord ad. us. vet,. Dado que la dermatopatía de origen hepatobiliar cursa con inflamación del hepatocito, como inmunoestimulante y modulador se administró Traumeel ad us vet. Al mismo tiempo como soporte orgánico se instauró Hepar Compositum, para estimular función hepática detoxificante; Flamosin Compositum ad us vet., como modulador de mucosas digestivas Y Solidago Compositum ad us vet, como apoyo a los riñones. Resumiendo lo planteado, se debe destacar el efecto observado del Traumeel en los queratinocitos, hepatocitos y nefronas de este individuo ya que se relaciona con otros estudios científicos donde demuestran los efectos moduladores de la inflamación adicional, al promover la cicatrización y reparación de los tejidos (GARNICA y col, 2018), (LAURENT ET AL, 2017).

Siguiendo el caso, en una etapa del tratamiento se administra ursacol ${ }^{\circledR}$ (Acido ursodexocicolico) a $15 \mathrm{mg} / \mathrm{kg}$ cada 24 horas como adyuvante en alteración colestásica hepatobiliar y en especial en la disolución de cálculos biliares. Los resultados obtenidos difieren de lo reportado en la literatura frente a la disolución de cálculos biliares, ya que después de 20 días de tratamiento con Ursacol® el hallazgo ecográfico evidenció la presencia de cálculos en la vesícula biliar. Frente a estos hallazgos se deduce que su efecto no tuvo resultados satisfactorios en este paciente debido a que la mayoría de los colelitos caninos y felinos se componen de sales de calcio (48\% son radiopacos) y de bilirrubinato. Según Soffer, el uso del ácido ursodexocicolico no tiene efecto satisfactorio sobre estos colelitos radiopacos (SOFFER, 2000). Por este motivo, se administró Chelidonium Hommacord, utilizado para colecistitis, colelitiasis, lesión hepática, hepatitis aguda y crónica; como drenador de la vesícula biliar en casos de obstrucción secundario a cálculos biliares junto con Hepar Compositum para la estimulación de la función de detoxificación hepática (MORENO, 2016)

(Vademécum, Eduka heel). Con este manejo, se evidencian efectos positivos al disolver los cálculos biliares del paciente en estudio demostrando efectividad del producto. Sin embargo, al no encontrar literatura de su uso en animales domésticos hace relevante mayores investigaciones del Chelidonium Hommacord.

Resumiendo, la predisposición racial también influye en los problemas dermatológicos, ya que han encontrado dermatosis de origen nutricional que en el pastor alemán están vinculadas al síndrome de mala asimilación (CARLOTTI y col, 2004). En el historial de vida del paciente, el animal presentó vomito y diarrea; al adquirir un proceso gastroentérico los enterocitos y las vellosidades intestinales quedan inmunocomprometidas iniciando síndrome de mala absorción. Estudios revelaron que existen posibles susceptibilidades subyacentes en el sistema inmune innato de perros y gatos con IBD, que demuestran aún más la intrínseca relación entre la microbiota intestinal y la salud del huésped (HONNEFFER y col, 2014). Es por esto que carencias nutricionales como deficiencias de biotina, de ácidos grasos esenciales, aminoácidos y Zinc pueden provocar lesiones cutáneas o lesiones costrosas debido a la degeneración de los queratinocitos (APPLETON y col, 2013) (MADRIL, 2016). Al principio se maneja terapia convencional, dado que no se tienen resultados de laboratorios inmediatos y se observa resultados desfavorables en las lesiones. Posterior se realiza un análisis más global del paciente, manejando conceptos de medicina biorreguladora de sistemas, identificando que las lesiones dermatológicas son generadas por las alteraciones en diferentes redes y sistemas, especialmente el hepático. Tomando la decisión de realizar un manejo mas integral y biorregulador en el paciente se observaron resultados positivos. Así que se reafirma, que la valoración integral del organismo en forma de redes de los sistemas involucrados, promoverán un 
mejor diagnóstico y por ende un efectivo tratamiento. Estos resultados coinciden con lo reportado por otros autores como GARZON, 2004, GARNICA y col, 2018, y ZURITA Y VALLEJO, 2017., sobre el uso de la homotoxicología como alternativa de tratamiento frente a enfermedades que requieran un manejo más completo.

En el caso clínico presentado se deduce que la alteración en los mecanismos de protección inmunitaria de la piel, el desbalance nutricional y las alteraciones hepáticas que presentaba el paciente, desencadenó las manifestaciones dermatológicas. Reconocer los diversos signos cutáneos es fundamental para diagnosticar a tiempo las enfermedades del hígado. El uso de Chelidonium Homaccord demuestra ser efectivo para disolver cálculos en la vesícula biliar de este paciente, sin embargo, faltan más estudios que argumenten su efectividad en el manejo de colelitiasis en pequeños animales. El uso de medicamentos biorreguladores de sistemas aplicados mediante infusión endovenosa y vía oral puede ser una opción de tratamiento eficaz en pacientes con síndrome hepatobiliar y afecciones dermatológicas. Realizar un buen manejo integral y profundizando más allá del sistema que manifiesta los síntomas, permitirá tener resultados más satisfactorios en los pacientes de medicina veterinaria y medicina humana, teniendo la posibilidad de solucionarlos desde sus diferentes sistemas asociado a redes.

\section{Conclusion}

- Aunque algunas manifestaciones cutaneas en caninos son inespecificas de alteraciones hepáticas, se deben tener en cuenta como hallazgos diferenciales primarios de una lesión de origen hepático. Faltan mas estudios científicos en animales domésticos que generen esa aproximación diagnostica de las enfermedades hepáticas manifestándose a través de la piel.

- En el caso clínico presentado se deduce que la alteración en los mecanismos de protección inmunitaria de la piel y el desbalance nutricional que presentaba el paciente, desencadenó las manifestaciones dermatológicas.

- El proceso de detoxificación e inmunomodulación que se utilizo en este paciente con Nux Vómica Hommacord, Lymphomyosot, Berberis Homaccord y Traumeel ad.us.vet demuestra ser de utilidad en el tratamiento alternativo de la dermatopatía de origen hepatobiliar, gracias a la limpieza y modulación del hepatocito, los queratinocitos y las nefronas comprometidas. Así mismo, de la elección de Hepar Compositum, Flamosin Compositum ad us vet. y Solidago Compositum ad us. vet. que gracias a sus diferentes organopreparados, proporcionaron una recuperación estructural y funcional de los diferentes órganos.

- El uso de Chelidonium Homaccord demuestra ser efectivo para disolver cálculos en la vesícula biliar de este paciente, sin embargo, faltan más estudios que argumenten su efectividad en el manejo de colelitiasis en pequeños animales.

- El uso de medicamentos biorreguladores de sistemas aplicados mediante infusión endovenosa y vía oral puede ser una opción de tratamiento eficaz en pacientes con síndrome hepatobiliar $y$ afecciones dermatológicas. Un buen manejo integrativo en los diferentes pacientes y no enfocándose únicamente en el sistema que manifiesta los síntomas permitirá tener resultados más satisfactorios en los pacientes de medicina veterinaria y medicina humana.

\section{Acknowledgements}

A todos los que hicieron posible la realización de este caso clínico, al propietario de la mascota que estuvo comprometido y fue responsable con el tratamiento del paciente. A los coordinadores de 
Heel que aceptaron el caso clínico y a David Quintana que estuvo presente en la organización y desarrollo del trabajo, por su paciencia, dedicación, y compromiso con el mismo.

\section{$\underline{\text { References }}$}

- Castrillón RLE, Palma RA, Padilla DC. La función inmunológica de la piel. Dermatol Rev Mex 2008;52(5):211-24.

- Manual de Dermatologia en pequeños animales y exóticos. 2da edición. BSAVA. Aiden Foster y Carol Foil. Ediciones Lexus. Barcelona 2012

- Honneffer JB, Minamoto Y, Suchodolski JS. Microbiota alterations in acute and chronic gastrointestinal inflammation of cats and dogs. World Journal of Gastroenterology. Estados Unidos. 2014; 20(44): 16489-16497. En línea: URL: http://www.wjgnet.com/10079327/full/v20/i44/16489.htm

- VINCENT, Thawley. Acute Liver Injury and Failure. Veterinary Clinics of North America: Small Animal Practice. Volume 47, Issue 3, May 2017, Pages 617-630

- Molly A. Weingarten, DVM and Allison A. Sande, DVM, DACVIM, DACVECC. Acute liver failure in dogs and cats Journal of Veterinary Emergency and Critical Care. Clinical practice review. 25(4) 2015, pp 455-473.

- ZALDIVAR OCHOA, Miriam. El sistema inmunológico de las mucosas. Revista Cubana Medicina General Integrativa [online]. 2002, vol.18, n.5. 352-354 p. Disponible en: $<$ http://scielo.sld.cu/scielo.php?script=sci_arttext\&pid=S0864 $21252002000500012 \& \operatorname{lng}=$ es\&nrm=iso $>$. ISSN 0864-2125.

- CASAS, Isabel. Uso de medicación homeopática y medicina biorreguladora: conocimiento del paciente. Tesis doctoral Universidad Complutense de Madrid, 2015. 92-93 p

- RODRIGUEZ, Carlos Arturo. BERISTAIN, Diana Marcela. Gastroenterología II. Hepatopatías en pequeñas especies. Medicina y Cirugía. Diplomado en medicina interna para perros y gatos. Asociación Michoacana de Médicos veterinarios de pequeñas especies. Morelia, Michoacán. México, 2018 en línea: http://148.210.21.170/bitstream/handle/20.500.11961/6498/diplomado\%20morelia\%20hepatopat\%C3\%ADas.pdf? sequence=1\&amp;isAllowed $=y$ 1-20 p.

- GARZÓN-TENJO, Sergio Antonio. Manejo biorregulador de la encefalomielitis infecciosa por distemper canino y Ehrlichia. Revista Facultad Ciencias Agropecuarias - FAGROPEC. Universidad de la Amazonia, Florencia - Caquetá. 7(2). Pp. 50- 54. Julio - diciembre de 2015.

- LOPEZ, Rocío del Pilar y ANDRADE, Rafael Enrique. Tejido linfoide y linfomas gástricos. Revista Colombiana de Gastroenterología. Educación médica continuada. Asociaciones colombianas de Gastroenterología, 2010 en línea: http://www.scielo.org.co/pdf/rcg/v25n4/v25n4a13.pdf. 409-422 p.

- MADRIL, Kevin. MEJIA, Nicole. PIEDRA, Carlos. VILLACRES, Carolina. Síndrome hepato cutáneo en perros. Universidad Central del Ecuador. Facultad de Medicina Veterinaria y Zootecnia. 2016.

- APPLETON, Amber y VANGERBEN, Olivia. Lo esencial en el metabolismo y Nutrición. Metabolismo de los ácidos grasos y las proteínas. Editorial el Sevier. Barcelona España. 2013 48-82 p.

- MIRA, Graciela A. Hepatopatías en caninos y felinos. Universidad de Buenos Aires. Argentina. 2014 en línea: http://dpd.fvet.uba.ar/cartelera/00014500.pdf 1-28 p.

- ZURITA, Paola y VALLEJO, Kleber, Valoración del medicamento homeopático, como terapia post extracción del tercer molar inferior incluido. Articulo científico, Ciencias Médicas. Facultad odontología. Universidad Central del Ecuador. Vol. 3, núm. 1, enero, 2017. 147-167 p. 
- Birnesser H, Oberbaum M, Kein P, Weisner M. The homeopathic preparation Traumeel S(r) compared with NSAIDS for symptomatic treatment of epicondylitis. J Musculoskelet Res 2004; 8(2):119-28.

- GARNICA-TELLEZ, D.; ARIAS-VAZQUEZ, P.I. y RAMIREZ-WAKAMATZU, M.A.. Eficacia de medicamentos antihomotóxicos en el tratamiento del síndrome miofascial cervical y de cintura escapular: estudio comparativo versus toxina botulínica tipo A. Rev. Soc. Esp. Dolor [online]. 2018, vol.25, n.2 [citado 2020-02-14], pp.86-93. Disponible en: $<$ http://scielo.isciii.es/scielo.php?script=sci_arttext\&pid=S1134$80462018000200086 \& \operatorname{lng}=\mathrm{es} \& n r m=\mathrm{iso}>$. ISSN 11348046. http://dx.doi.org/10.20986/resed.2017.3594/2017

- SMIT, Alta. Tratamiento de las enfermedades musculo esqueléticas. Revista de Medicina Biológica. Vol. 17, № 2 (OCT), 2004. 53-60 p. En línea: https://dialnet.unirioja.es/servlet/articulo?codigo $=4151684$

- ADELWOHRER, Norbert. Matriz extracelular, $\mathrm{pH}$ y potencial redox. Revista de Medicina Biológica. Vol. 17, №. 2 (OCT), 2004. 77-78 p. En linea: https://dialnet.unirioja.es/servlet/articulo? $\operatorname{codigo}=4151815$

- RACANCO DELGADO, J. Jesús; MENDEZ AGUILAR, Rosa Elena; AGUILAR BOBADILLA, Joaquín y SALAS GARRIDO, Gerardo. Colelitiasis y coledocolitiasis obstructiva en un gato doméstico: Informe de un caso. Vet. Méx [online]. 2009, vol.40, n.3 [citado 2020-02-14], pp.269-274. Disponible en: <http://www.scielo.org.mx/scielo.php? script=sci_arttext\&pid=S0301-50922009000300005\&lng=es\&nrm=iso $>$. ISSN 0301-5092.

- SOFFER, Sion Farca. Tratamiento no quirúrgico de la litiasis vesicular Rev Fac Med UNAM Vol.43 No.4 Julio-Agosto, 2000. En línea: http://www.ejournal.unam.mx/rfm/no434/RFM43406.pdf 140-142p.

- SCHNEIDERA, Christian, SCHNEIDERB, Berthold, HANISCHC, Juergen y HASELEND, Robbertvan The role of a homoeopathic preparation compared with conventional therapy in the treatment of injuries: An observational cohort study. Complementary Therapies in Medicine Volume 16, Issue 1, February 2008, 22-27 p.

- MORENO, Angela. Perspectiva Del Manejo Homeopático De Las Enfermedades Tropicales. Universidad Nacional de Colombia Facultad de Medicina Maestría en Medicina Alternativa. Monografía, Bogotá, 2016. 1-131 p. http://www.bdigital.unal.edu.co/52658/7/angelamorenorey.2016.pdf

- Vademecum Eduka Heel. https://www.eduka-heel.com/wpcontent/vademecum/08_chelidoniumgotas.html

- PATIÑO, Sandra L, MONROY, Andrea C., y SUARES, Ma Consuelo. Medicamentos homeopáticos útiles en el tratamiento de afecciones del sistema. Homeopatía usada en odontología. Revisión narrativa de la literatura. Acta Odontol. Colomb., Volumen 1, Número 1, 2011, 39-52 p.

- CENTER, S. A. Nutritional Support for Dogs and Cats with Hepatobiliary Disease. The Journal of Nutrition, Volume 128, Issue 12, December 1998, Pages 2733S-2746S En: https://doi.org/10.1093/jn/128.12.2733S

- COUTO, Guillermo y NELSON, Richard W., Medicina Interna de Pequeños Animales. Sexta edición. Grupo Asis Biomedia SL. 2020. Parte IV. Trastornos del sistema hepatobiliar y del páncreas exocrino. Capitulo 36. Enfermedades hepatobiliares en el perro. Consideraciones generales y Síndrome Hepatocutaneo y Dermatitis necrolitica superficial. 584-616 p.

- DOGRA, Sunil., JINDAL, R. Cutaneous manifestations of common liver diseases. Review Article. Journal of Clinical and Experimental Hepatology. Vol. 1, Issue 3, December 2011. 177-184 p.

- DRAGONETTI, Ana María., STORNELLI, María Alejandra. Enfermedad Hepatobiliar Ictericia. Revisiones. Facultad de Ciencias Veterinarias. Universidad Nacional de la Plata, Argentina. Veterinaria Cuyana. Vol. 1 No 1. 2006. 29-35 p. En: 
http://sedici.unlp.edu.ar/bitstream/handle/10915/119132/Documento_completo.pdf?

sequence $=1$

- ESPINOZA, Yeinis Paola., MOLINA, Verónica., RESTREPO, Juan Carlos. Manifestaciones dermatológicas de las enfermedades hepáticas: un enfoque para el médico general. Medicina y Laboratorio: Programa de Educación Médica Contínua Certificada Universidad de Antioquia, Edimeco. Vol. 18 Números 5-6. 2012. 229-238 p. En: https://www.medigraphic.com/pdfs/medlab/myl-2012/myl125-6c.pdf

- GHOSN, Samer., GHANIKIBBI, Abdul. Cutaneous Manifestations of liver diseases. Clinics in Dermatology. Volume 26, Issue 3. May-June 2008. 274-282 p. En: https://doi.org/10.1016/j.clindermatol.2008.02.001

- HAZIN, Ribhi, TAREK, I., RAJAB, Abu., JAMIL, Y., ABUZETUN, Y ZEIN. Recognizing and treating cutaneous signs of liver disease. Cleveland Clinic Journal of Medicine October 2009. Vol. 76 No (10) 599-606 p. En: DOI: https://doi.org/10.3949/ccjm.76A.08113

- ISASI, I., MUÑOZ, G., RAMÍREZ, G. BARDAGI, M. Dermatitis exfoliativa y alopecia asociada a hepatitis en un conejo. Universidad Autónoma de Barcelona. Clin. Vet. Peq. Animales. 2012, Vol. 32 No. (3) 175-179 p. En: https://core.ac.uk/download/pdf/78525191.pdf

- KOULAOUZIDIS, Bhat., MOSCHOS. skin manifestations of liver diseases. Annals of hepatology. Vol. 6. Issue 3, julio-septiembre 2007. 181-184 p.

- MELA, a. MANCUSO, a. Y a. K. BURROUGHS. Review article pruritus in colestatic and other liver diseases. Blackwell Publishing Ltd., Aliment Pharmacol Ther. November 2003. Vol. 17. 857-870 p. En: doi: 10.1046/j.0269-2813.2003.01458.x

- PATEL, Ashaki., KATZ, Kimberly., y GORDON, Kenneth. Cutaneous manifestations of chronic liver diseases. Department of Dermatology, Medical College of Wisconsin 2020. El Sevier. 1-10 p. En: https://scihub.se/https://doi.org/10.1016/j.cld.2020.04.003

- SAEZ, Ma Luisa. Manifestaciones cutáneas de las enfermedades sistémicas. Revista médica clínica Las Condes. Volumen 22, Issue 6, noviembre 2011. 749-756 p. En: https://doi.org/10.1016/S0716-8640(11)70487-4

- SALAS, Carrasco. E.; GRANDEZ, Rodríguez. R. Hepatocutaneous syndrome or superficial necrolytic dermatitis in a dog: a case report. Lima-Perú. 2013. 1-10 p. En: https://www.researchgate.net/profile/Elia-Salas

- ST, LAURENT, Bernd Seilheimer, Michael Tackett, Jianhua Zhou, Dmitry Shtokalo, Yuri Vyatkin, Maxim Ri, Ian Toma, Dan Jones, Timothy A McCaffrey. Deep Sequencing Transcriptome Analysis of Murine Wound Healing: Effects of a Multicomponent, Multitarget Natural Product Therapy-Tr14. 2017; Frontiers in Molecular Biosciencies. 4; 57. DOI: $10.3389 /$ fmolb.2017.00057

- SuAREZ, M., GONZALES, E., SEOANE, A., SANTAMARINA, G. Caso clínico de Medicina Interna. Departamento de Anatomía, Producción Animal y Ciencias Clínicas Veterinarias. Hospital Veterinario Universitario Rof Codina. Facultad de Veterinaria. USC. Vol. 37, No 3. 2017. 202-208 p. En:

https://www.clinvetpeqanim.com/img/pdf/1470467844.pdf

\section{Attachments}




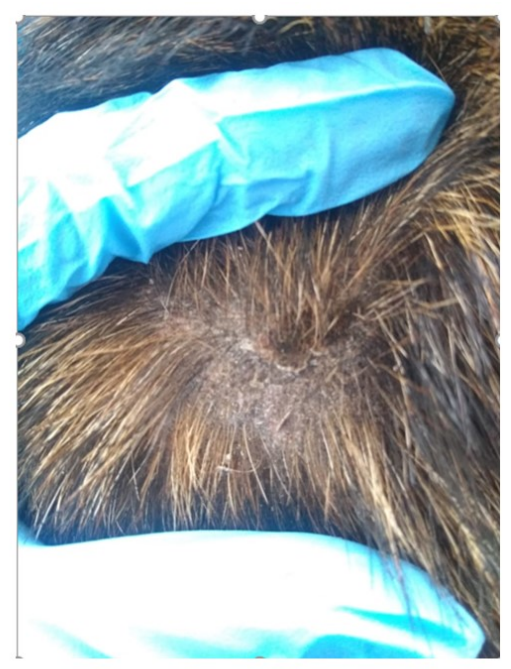

Imagen 1: Consulta inicial 22 de octubre de 2019. Alopecia focalizada, descamación, eritema, prurito, lesiones costrosas

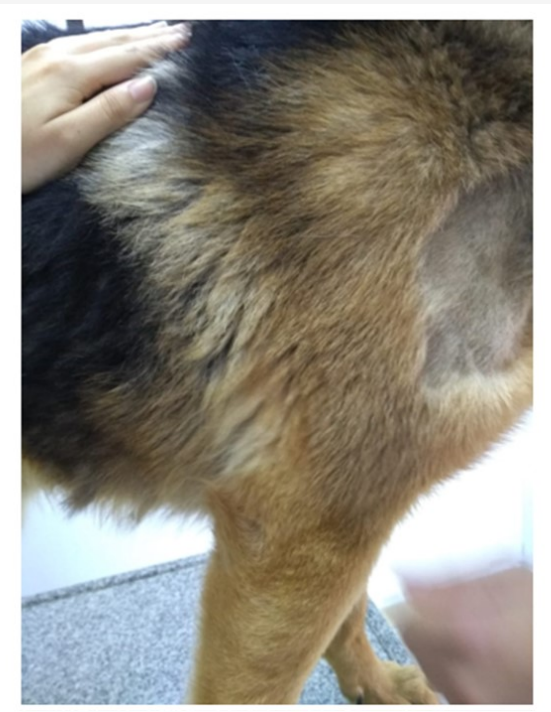

Imagen 1.1: 22 de octubre de 2019. Alopecia focalizada en costados y zona escapular 


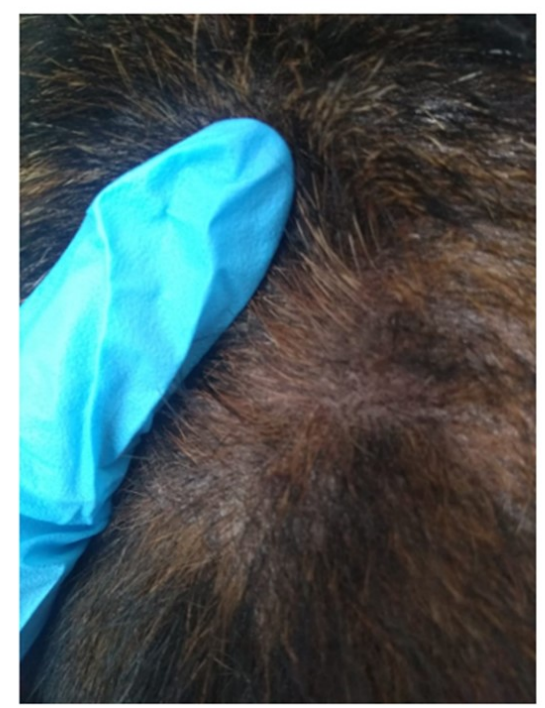

Imagen 1.2: 22 de octubre de 2019. Lesiones eritematosas, hipotricosis, descamación.

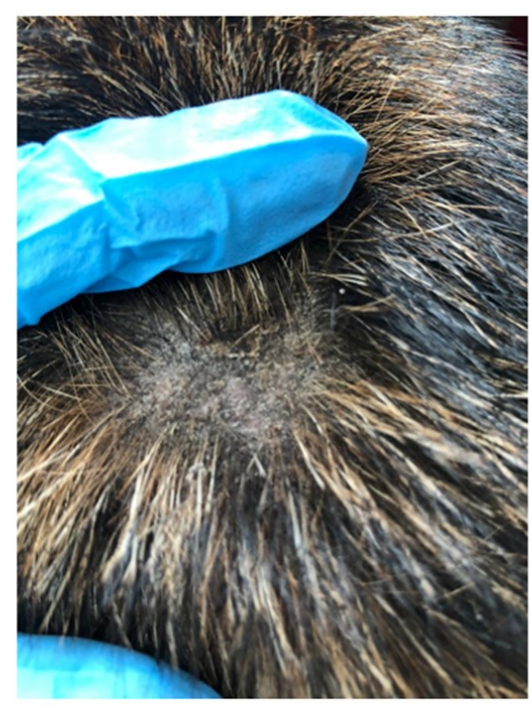

Imagen 1.3: 22 de Octubre de 2019. Lesión costrosa zona lumbar 


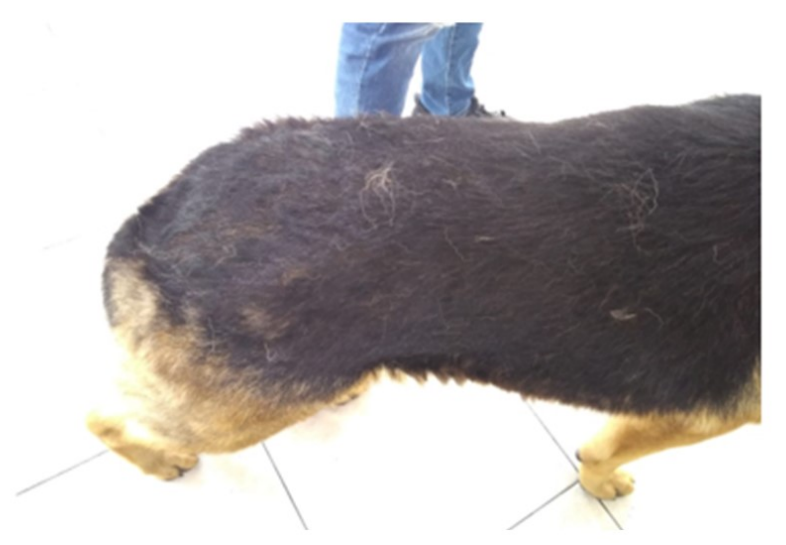

Imagen 1.4: 22 de octubre de 2019. Excesiva caida de pelo, pelo hirsuto y opaco.

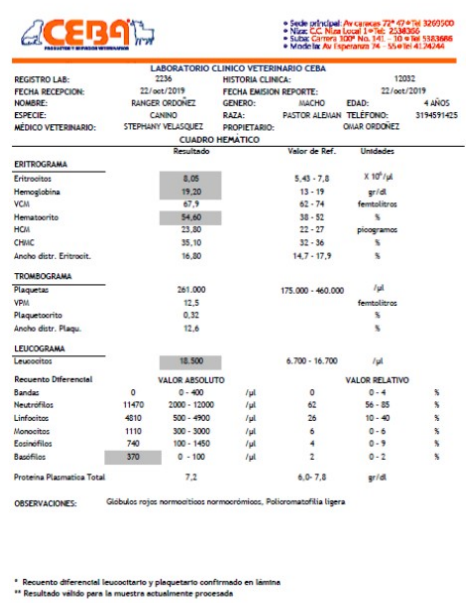

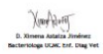

Imagen 2: 22 de octubre de 2019. Hemograma completo, hemoconcentración, leucocitosis leve y basofilia 


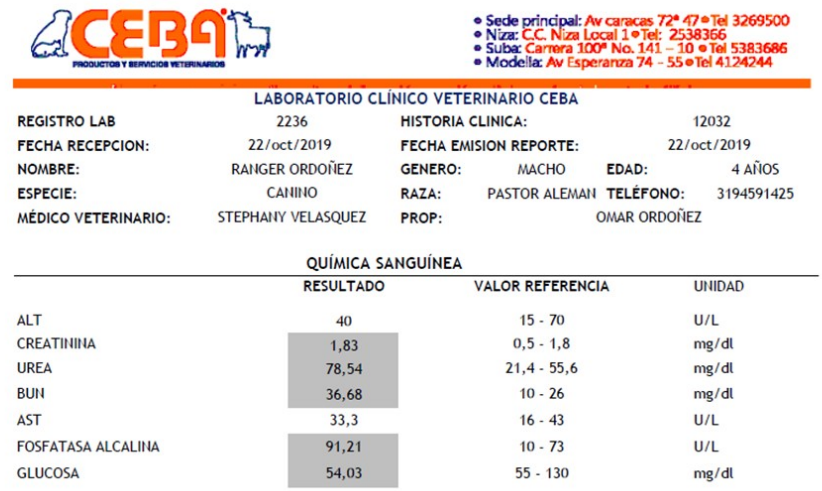

Imagen 2.1: 22 de octubre de 2019. Quimicas sanguineas

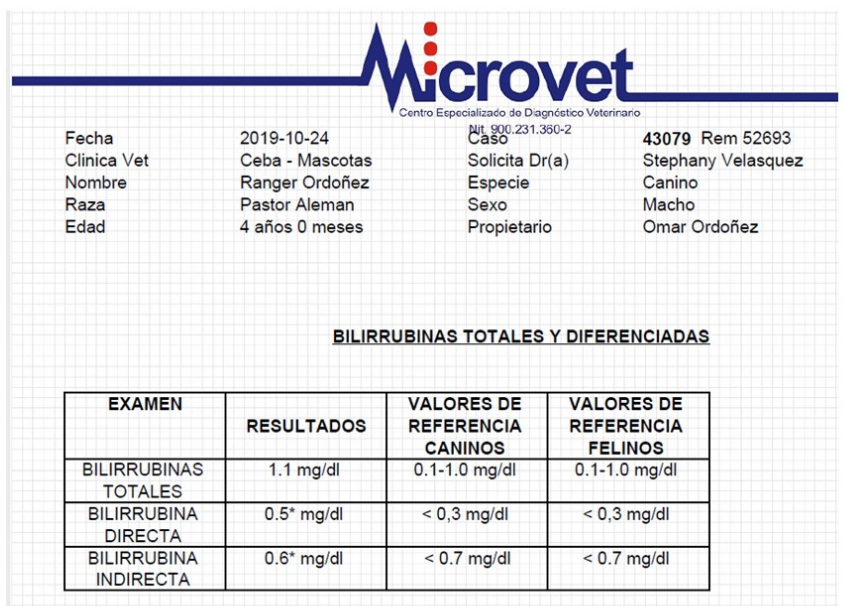

Imagen 2.2: 24 de octubre de 2019. Bilirrubinas totales y diferenciadas. Elevacion de bilirrubina directa e indirecta 


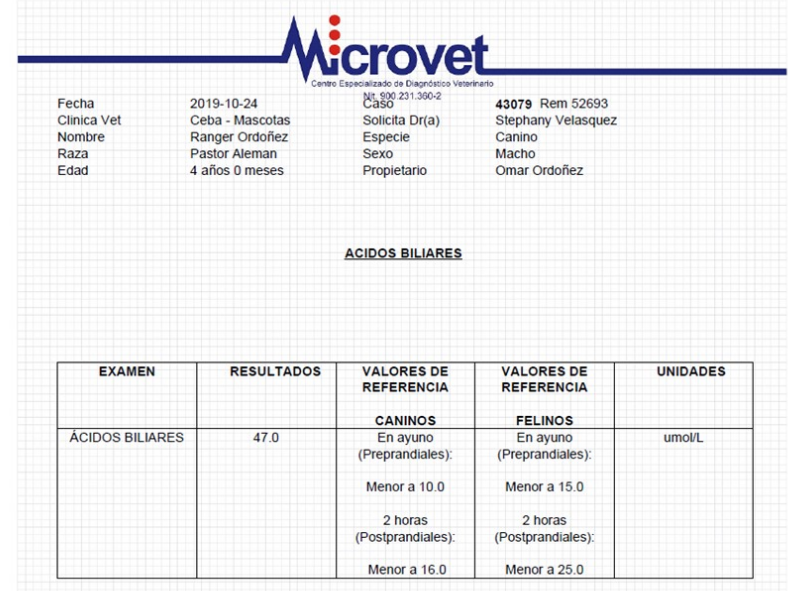

Imagen 2.3: 24 de octubre de 2019. Elevación marcada de ácidos biliares

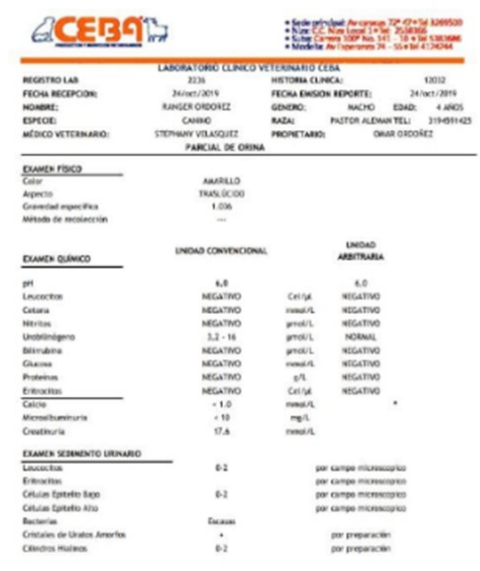

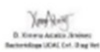

Imagen 2.4: 24 de octubre de 2019. Uroanalisis, presencia de Urobilinógeno y cilindros hialinos 

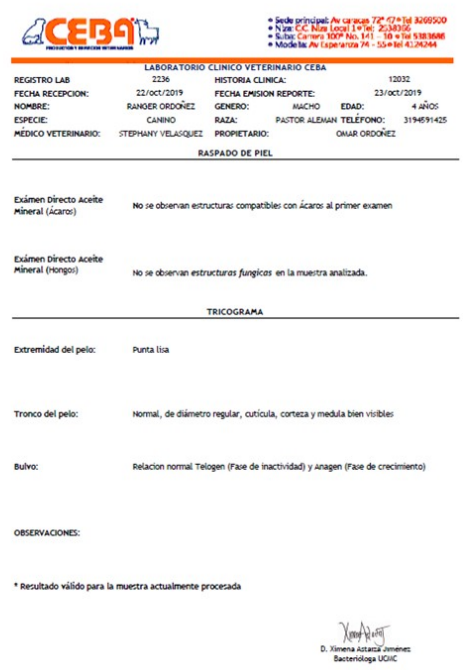

Imagen 2.5: 22 de octubre de 2019. Raspado de piel y tricograma sin novedades

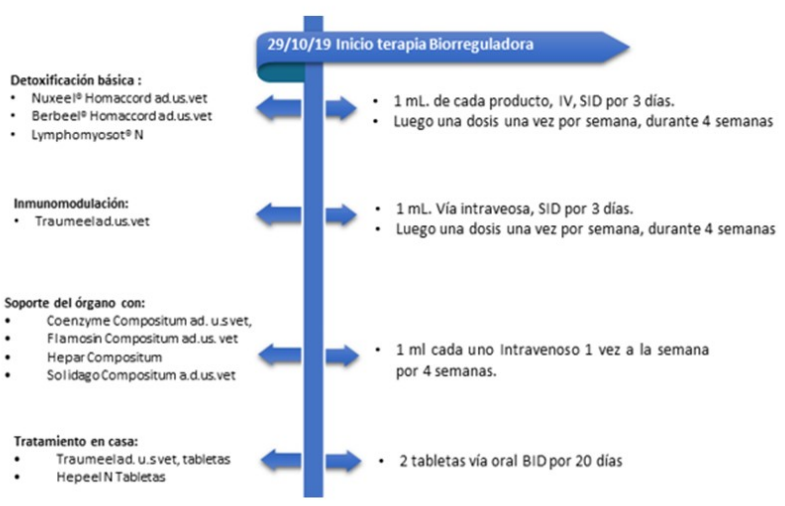

Tratamiento

Contincion lassuercterapias intravenosas y dieta medicar

Chel idonium Homaccord NT Gotas, 10 gotas por 20 dias

Se suspende Ursacol par falta de efertividad (Ecografia).

Imagen 3. 29 de octubre de 2019. Tratamiento biorregulador Heel: Detoxificacion basica, Inmunomodulacion $y$ Soporte al órgano. 


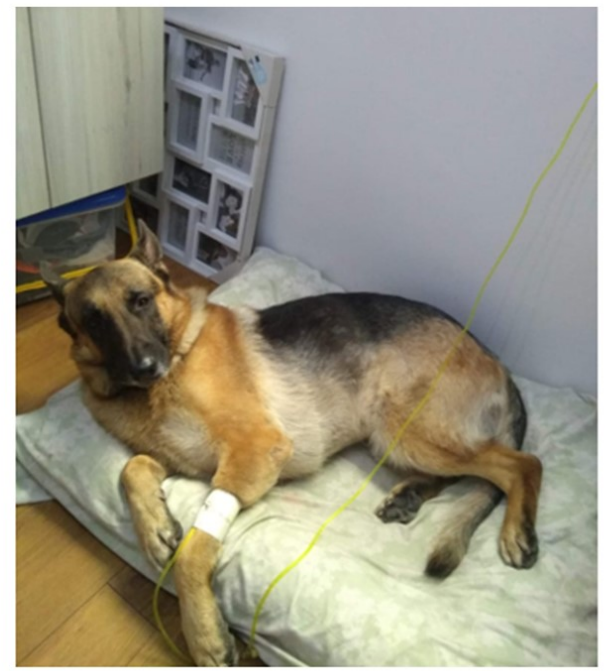

Imagen 3.1: 29 de Octubre de 2019. Sueroterapias Endovenosas con Medicina Biorreguladora Heel

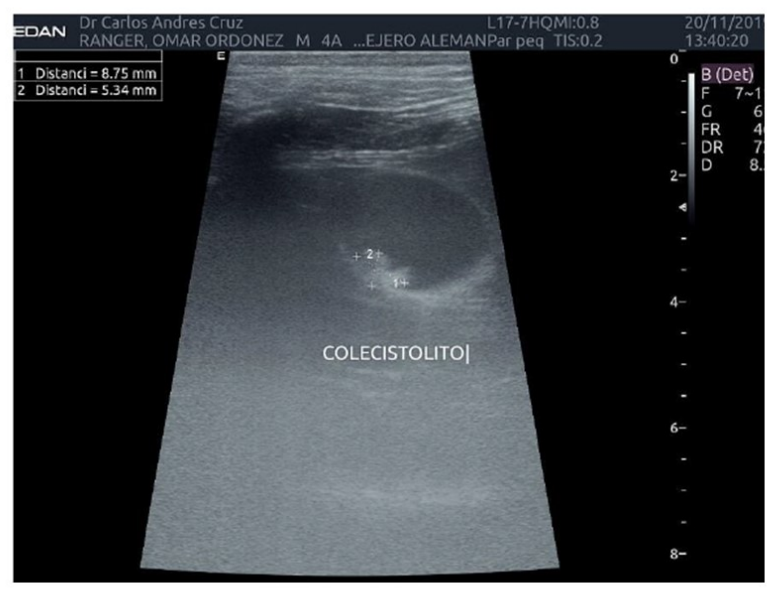

Imagen 4: 22 de noviembre de 2019. Colecistolitos hallados en ecografia 

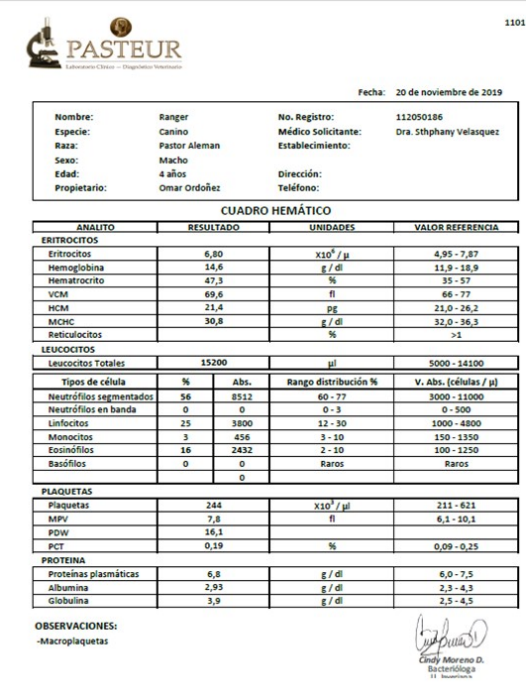

Imagen 5: 20 de noviembre de 2019. Hemograma completo de control. Leucocitosis leve con eosinofilia.

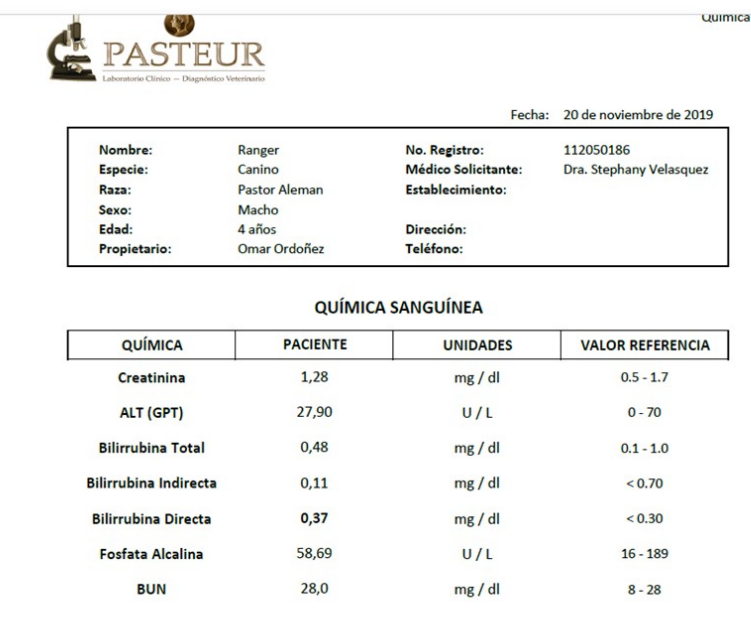

Imagen 5.1: 20 de noviembre de 2019. Quimicas sanguineas de control sin alteraciones 


\begin{tabular}{|c|c|c|c|c|c|}
\hline somber. & PANGFR & Historia Clínica & $.2 \mathrm{~B}$ & Codion & 4020 \\
\hline Nombre : & KANGEK & Histona limica & N.K. & Codigo & 19294 \\
\hline Especi & :CANINC & Clinica Veterina & : ADRIANA MILENA RODRIGUEZ PALACIOS & Fecha Ingreso & : Noviembre 21/2019 \\
\hline Sexo & : Macho & Solicitador 1 & :DRA. ADRIANA RO & & : Novenombe 2 2/1/2 \\
\hline
\end{tabular}

Edad : 4 Años

QUIMICA SANGUINEA

ACIDOS BLIARES

$18.0 \mathrm{umol} / \mathrm{L}$

V.N. EN AYUNO $0-8$ umol/L

METODO

Enzimatico

(R) Valor confirmado

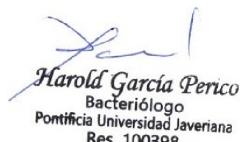

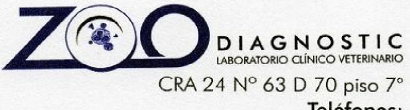

(57) 12117965 (57) 12551343

Cel $3107649029-3133973205$

uww.zoodiagnostic.com
Bogotá - Colombia

Imagen 5.2: 20 de noviembre de 2019. Disminución de ácidos biliares 


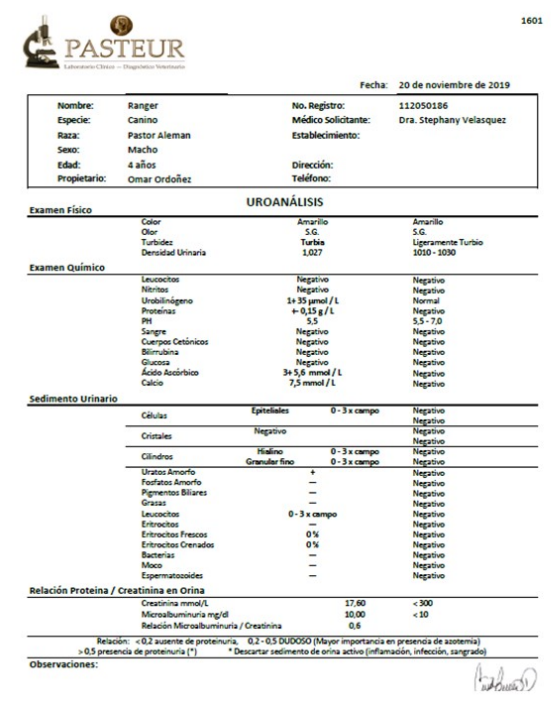

Imagen 5.3: 20 de noviembre de 2019. Uroanalisis control. leve proteinuria, presencia ácido ascórbico, calcio, cilindros hialinos leves 

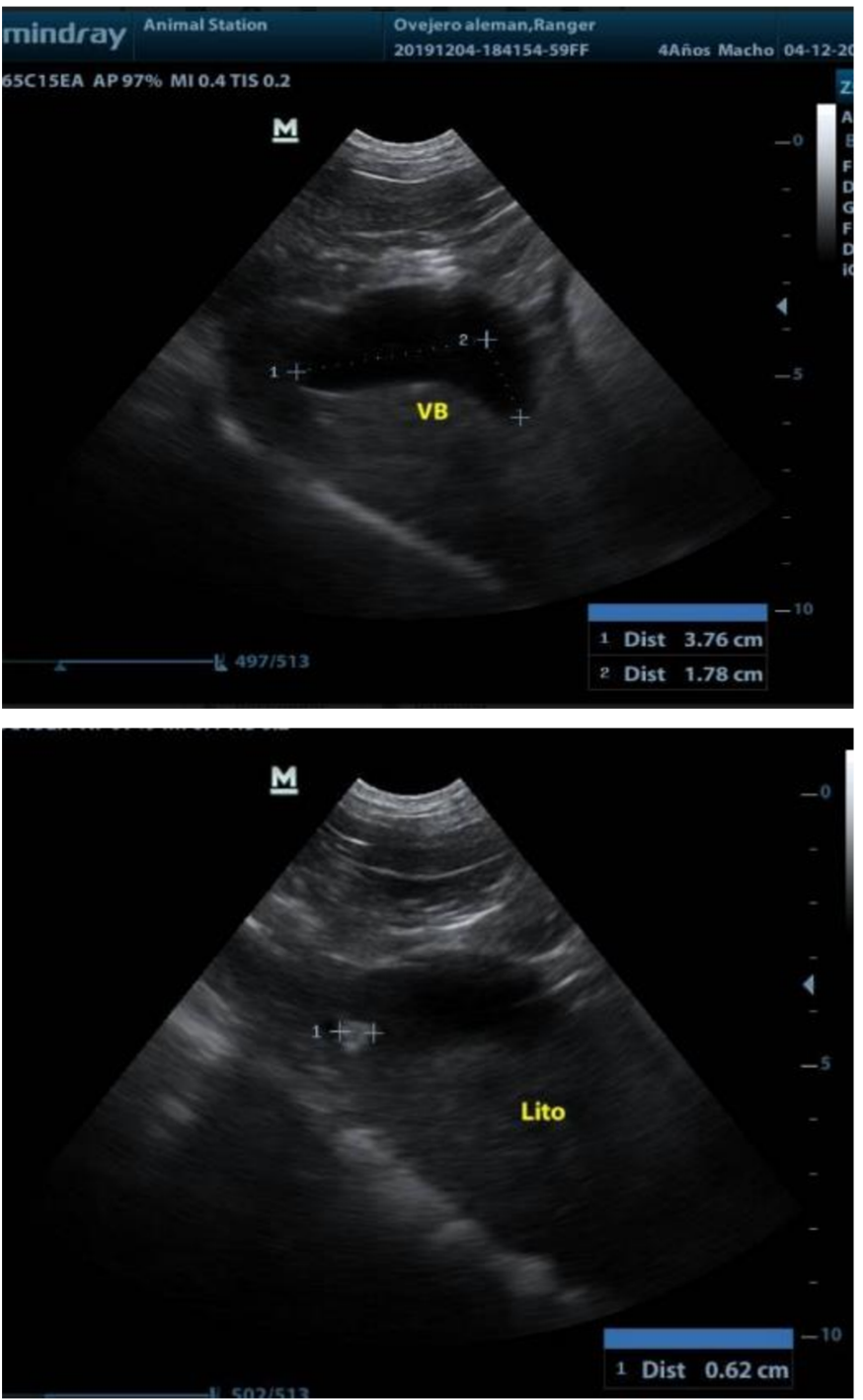

Imagen 6: 4 de Diciembre de 2019. Se evidencia solo 1 cistolito y con disminucion de tamaño 


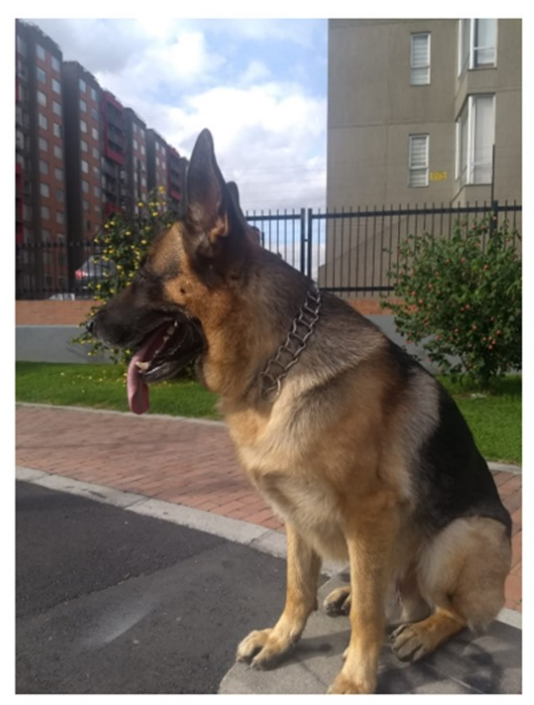

Imagen 7: Tomada el 4 de Diciembre de 2019. Mejora en condición corporal, estado de ánimo y pelaje sano.

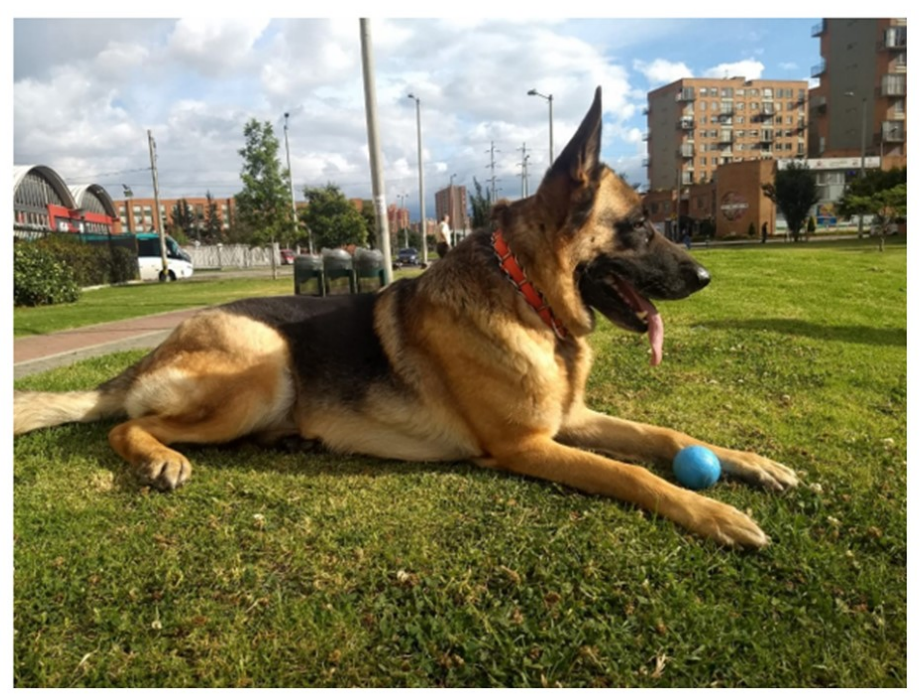

Imagen 8: Tomada el 10 de Diciembre de 2019. Recuperación lesiones dermatológicas 
CONSENTIMIENTO INFORMADO DEL PROPIETARIO DEL PACIENTE DELL ESTUDIO CLIIIIICO

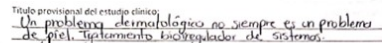

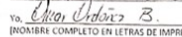

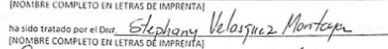

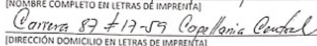

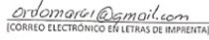

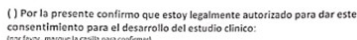

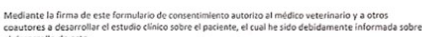

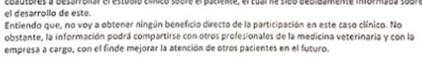

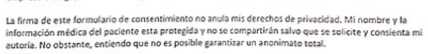

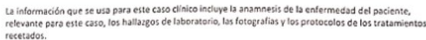

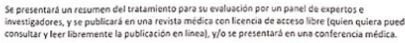

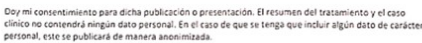

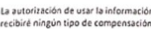

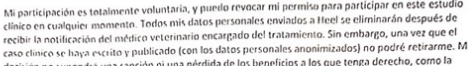

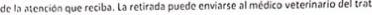

Mediant la firma de este formulario confirmo que:

政

Se me ha informado acerca de los riesesesy tos heneficios, si los hubiera, de

permititi usar mi información en este caso clinica

caso clinico

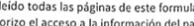

-

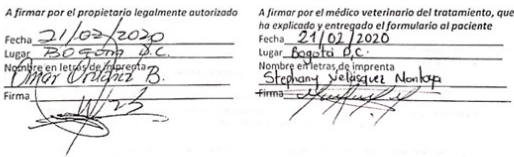

Imagen 9: Consentimiento informado propietario 


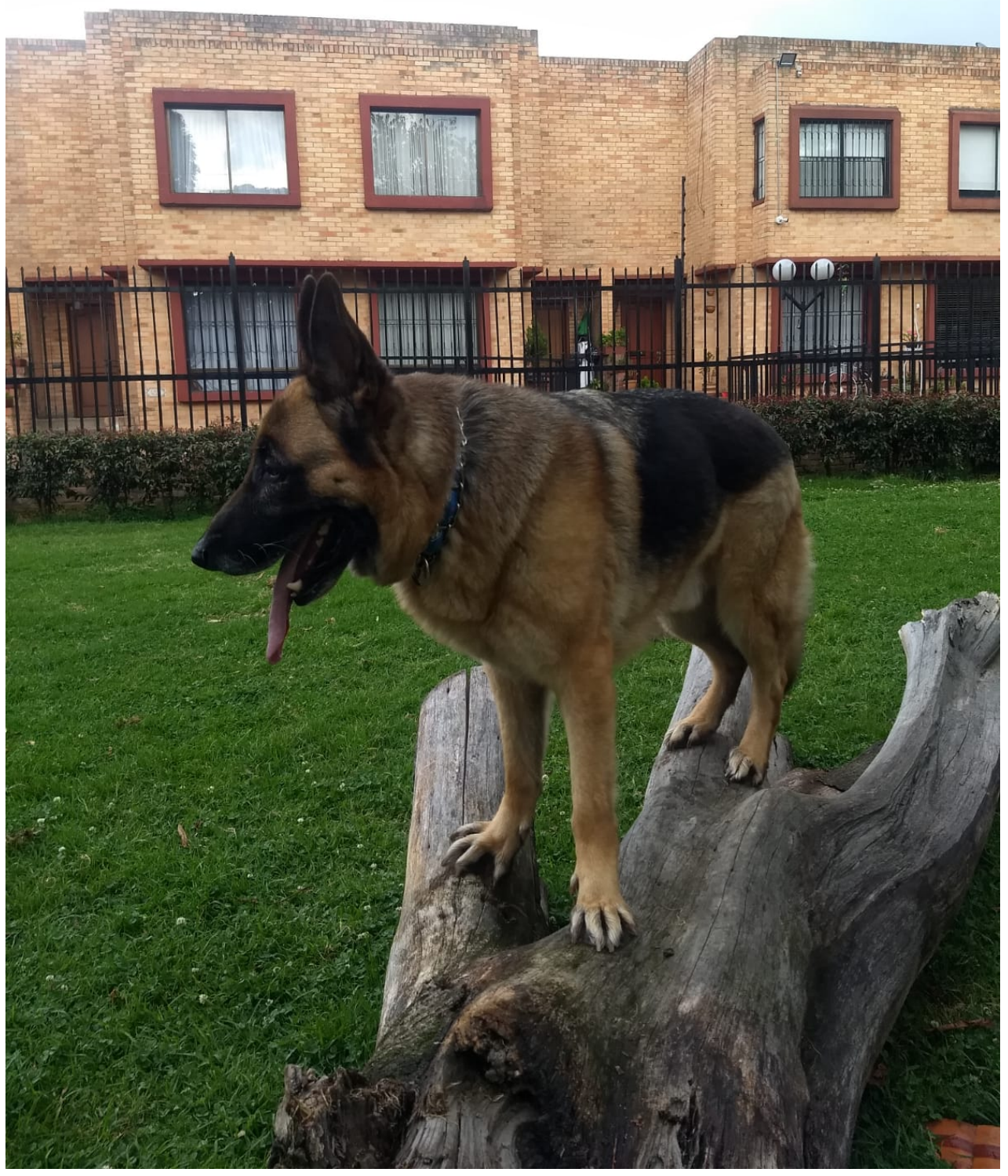

Diciembre 02 de 2021, 2 años después el paciente goza de buena salud y sin recaídas 


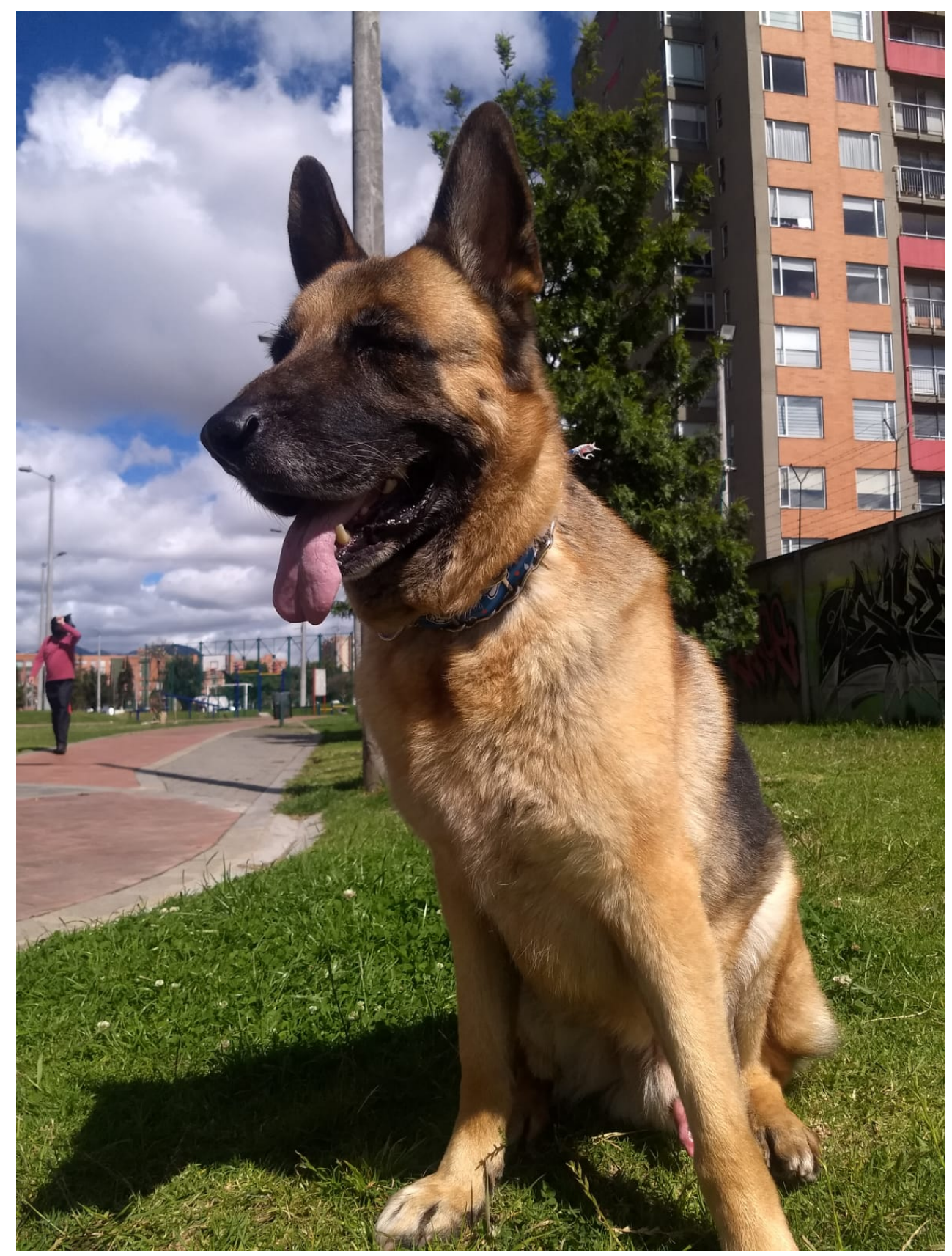

Diciembre de 2021 evolución satisfactoria pasados 2 años del tratamiento. 